\title{
Language, Space and the theory of Semantic Forms
}

\author{
Yves-Marie Visetti* \\ In A. Carsetti (Ed), Seeing, Thinking and Knowing - Meaning and Self-Organisation in Vision and Thought, \\ pp. 245-275, 2004, Kluwer Academic Publishers, Dordrecht.
}

\begin{abstract}
This paper, which is a synthesis of several previous publications, analyzes some of the principles according to which it is possible to build an analogy, or even a continuity, between language and perception. Several misleading options are identified, arising from erroneous models of perception, and the non-taking into account of polysemy as a fundamental property of language. Starting from the example of prepositions, we challenge these difficulties, in order to put forth general semantic principles, applicable to all categories of words and constructions. The key question of the relation between spatial and less- or non spatial uses of words will lead us to come back to the Gestalt and phenomenological theories of perception and action, which more than ever offer irreplaceable insights for semantics. We then sketch a radically dynamical theoretical framework, which gives a fundamental role to the mathematical concepts of instability. On this basis, the microgenesis of what we call Semantic Forms can be distributed between three layers of meaning, or 'stabilization and development phases', named motifs, profiles, and themes. Taken together, they shape linguistic structure and semantic activity. They apply in exactly the same way in lexical as well as in grammatical semantics, whose distinction is reassessed in conclusion.
\end{abstract}

Keywords: Semantic Form, phenomenology, Gestalt, microgenesis, cognitive linguistics, grammar, space, polysemy, motif, profile, theme, instability, stabilization, complex system

Table of contents

\section{Language, Space and the theory of Semantic Forms}

\section{Introduction}

2. From Schemes to Motifs: the case of prepositions

Some sketchy considerations on French Prepositions

3. Towards a phenomenological and Gestalt theory of Semantic Forms

3.1 Gestalt, Phenomenology, and Language Activity

3.2 An insight into the semantics of Nouns

4. The Microgenesis of Semantic Forms: Motifs, Profiles, Themes

4.1 Motifs

4.2 Profiles

4.3 Themes

6. Conclusion: the nature and place of Grammar in a dynamical theory of Semantic Forms

\section{References}

\footnotetext{
* CREA-CNRS, 1 rue Descartes, 75005 Paris France

e-mail : visetti@ens.fr
} 


\section{Introduction}

Phenomenological and Gestalt perspectives have become increasingly important in linguistics, which should lead to better exchanges with semiotics and cognitive sciences. Cognitive linguistics, and to a certain extent what is known as linguistique de l'énonciation, have led the way. ${ }^{1}$ They have each in their own way established something of a Kantian schematism at the center of their theoretical perspective, developing on this basis what we might call a theory of semantic forms. They have introduced genuine semantic topological spaces, and attempted to describe the dynamics of the instantiation and transformation of the linguistic schemes they postulate. It is thus possible, up to a certain point, to conceive the construction of meaning as a construction of forms, and in so doing, to analyze resemblances and differences between these various processes. As a result, the idea of grammar itself has been modified, and centered upon a universal linguistic schematism, which supposedly organizes the values of all units and constructions. At the same time a certain understanding of the phenomenon of polysemy has been obtained, at least as far as this grammatical level is concerned.

However, a closer analysis reveals a number of difficulties, which call for a better understanding of what a genuine phenomenological and Gestalt framework should be in semantics. First, if we agree with the fact that there is a privileged relation, or some kind of similar organization, between language and perception, we should make more precise the general theory of perception (and jointly of action !) which we take as a reference. Secondly, if we also agree with the idea of a specifically linguistic schematism, analog to, but different from, what is needed for 'external' perception-and-action, its realm of dimensions should be determined: but we note here that there is a real, important disagreement between the authors. Thirdly, if we view language activity as a construction of genuine, 'internal' semantic forms based on linguistic schemes, it is obvious that polysemic words should correspond to transposable and plastic schemes: but the works we have just evoked remain very vague on this point; most of the time they propose lists of cases rather than genuine transposition and/or transformation processes. As a matter of fact, very few authors consider polysemy as a fundamental property of language which should be taken into account by linguistics from the very beginning.

Furthermore, all these approaches acknowledge the importance of the spatial and/or physical uses of linguistic units, i.e. those uses which seem to be exclusively dedicated to qualify the topological, geometrical or physical structure of the tangible world. But now a question arises: what is the relationship between these uses, and all the other uses of the same units, which, depending on the context, can signify a great variety of meanings? For instance, what is the 'logic' connecting the different uses of the English preposition $O N$, like in book on the table (spatial use), departure on Monday (temporal), tax on income or to count on one's friends ('support' or 'foundation')? Should we consider that the spatial or physical values of $O N$ are in a sense a basis for all the others? Are they more typical? Or should we

\footnotetext{
${ }^{1}$ Under the French heading linguistique de l'énonciation, we mean a linguistic current which can be traced back to K. Bühler (1934), through the work of E. Benveniste (1966/1974), and more recently, through the important contributions of A. Culioli (1990/1999), O. Ducrot (1984), J.C. Anscombre and O. Ducrot (1983).
} 
put all the uses on the same footing, and derive the various meanings from a single more generic principle?

In this paper we will show how to escape these false dilemmas, and how to better assess the continuity between the perception of the tangible world, and the perception of the Semantic Forms upon which we intend to build a theory. Starting from the key question of prepositions and of the relation between their spatial and less- or non spatial uses, we shall try to put forth general semantic principles, applicable to all categories of words and constructions (section 2). After that (section 3), we shall come back very briefly to Gestalt and phenomenological theories of perception, stressing the fact that they are semiotic theories, and not only morphological or 'configurational' theories of perception. As an immediate application to semantics, we will show the interest of this kind of approach to clarify the meaning of other categories of polysemic words (e.g. nouns). We shall then propose (section 4) - but in a very sketchy way - some general postulates for a microgenetic theory of Semantic Forms, based upon the mathematical notion of instability. The theory postulates 3 layers of meaning (or 'phases' of stabilization), called motifs, profiles, and themes. Taken together, they shape linguistic structure and semantic activity. They apply in exactly the same way in lexical as well as in grammatical semantics. Actually, they are conceived in the perspective of being integrated more tightly into a global textual semantics, very akin to the one developed by F. Rastier $(1987,1989,1994,2000)$. Finally, we come back in conclusion to what should be the nature and place of grammar in a theory of Semantic Forms.

This paper motivates and sketches a theory of Semantic Forms, which is a joint work with P. Cadiot, arising from our common interest for semantics, Gestalt theory, phenomenology, and complex dynamical models (e.g. Visetti 1994, 2001; see also Rosenthal and Visetti 1999, 2003). Examples and their specific analyses - sometimes slightly reformulated - have been taken from P. Cadiot's previous works. We propose here a synthesis of several previous publications, with a special stress on the relation between language and space, and on the grammatical dimensions of meaning. The semantics of prepositions, and more generally grammatical semantics, should be considered as a very important starting point, and a first application of our theory. However our real purpose is much more global, and goes beyond that: we try to put from the very beginning - at least at a theoretical level - the whole semantics under the pressure of a fully dynamical, discursive, and diachronic perspective. The interested reader will find a much more detailed presentation in our recent book (Cadiot $\&$ Visetti 2001a). ${ }^{2}$

\section{From Schemes to Motifs: the case of prepositions}

All the different trends in Cognitive Linguistics have placed the question of grammar in the foreground of their works, and have developed specific and original conceptions of it. As a matter of fact, they have severely criticized the autonomy of syntax postulated by generative linguistics in the line of Chomsky's work. But they have maintained a clear cut

\footnotetext{
${ }^{2}$ For a full presentation, see our book: Pour une théorie des formes sémantiques - Motifs, Profils, Thèmes (Cadiot \& Visetti, 2001a). See also Cadiot 1999a, 1999b, 2002 ; Cadiot \& Visetti 2001b, 2002; Visetti \& Cadiot 2000, 2002.
} 
separation between structure and content: 'structure' refers to a central and universal schematic level of meaning, called grammatical, which extends to all units and constructions; 'content' refers to all the remaining dimensions (concepts, notions, domains...), specifically brought by the lexicon. Grammar is therefore a kind of imagery, a way of structuring, of giving 'configurations' to all semantic domains, and also to the 'scenes' evoked by speech. Imagery includes:

- structural organization of 'scenes' (space, time, movement, figure/ground or target/landmark organization, separation between entities and processes)

- perspective (point of view, ways of going over the scene)

- distribution of attention (focusing, stressing)

- and, for Talmy or Vandeloise (not for Langacker), some less configurational dimensions, like the system of forces, or dimensions like control, or access.

For all these authors, this kind of schematism is specific to language (e.g. topological, not metric), but has many common properties with perception of external space.

Most often there is a trend towards relying on a very general psychological prototype, according to which language, at its most fundamental level, encodes tangible and/or physical structures. Therefore, in order to describe all kinds of categories of words, linguistics should favor spatial and/or concrete uses, and even take them as a primary basis for all the other ones. This idea leads in cognitive semantics, and also in grammaticalization theories, to a hierarchy of meanings, which starts from spatial or physical values, taken as literal meanings, up to temporal or abstract meanings, which are supposed to be derived from the previous ones by some kind of metaphorical transfer process. However, authors like Lakoff, Langacker, Talmy or Vandeloise underline that these primary values proceed from specifically linguistic schemes, which should not be confused with perceptive 'external' structures: indeed they are far more schematic, and at the same time genuinely linguistic, since for example they shape space by introducing 'fictive' contours or 'fictive' motions (Talmy). But in spite of these very important addings, the primacy (and/or the prototypical status) of a certain kind of spatial and physical meanings is not really questioned. Furthermore, schematical relations between language and perception often rely on a very peculiar conception of the spatial and physical experience, which fails to appreciate the true nature of what the phenomenological tradition names the 'immediate experience' of subjects. It amounts to a reduction of this 'immediate experience' to a purely external space, and to a purely externalized physics of 'forces', both separated from their motor, intentional and intersubjective (even maybe social and cultural) sources. In this external space, language would identify relations between 'trajectors' and 'landmarks', conceived as independent, separate, individuals or places, entirely pre-existing to the relations they enter in.

We think that this type of analysis extends to semantics a very questionable conception of perception, which stems from ontological prejudices, and not from rigorous descriptions. As a consequence of this wrong starting point, some works in the field of grammar retain only a very poor and abstract schematism; while others, or even sometimes the same works, address only the spatial or physical uses, hoping that the thus created gap between these uses and all the others will be filled by an appeal to the magical notion of metaphor.

More precisely, concerning the type of those linguistic schemes currently postulated by LC, and their relation to our external, everyday perception, two main attitudes can be distinguished: 
- sometimes (Langacker, particularly) the realm of dimensions prescribed by the historical Kantian framework is centered on purely abstract 'configurational' dimensions (abstract topology, abstract dynamics) ; those dimensions are supposed to be a permanent and obligatory basis of language in all semantic domains ; on the contrary, dimensions like 'forces' (and a fortiori dimensions like interiority, animacy, agency,...) are considered as less grammatical, secondary dimensions, coming only from more or less prototypical uses (e.g. referring to the external perceived space) ; they can only add themselves to the configurational dimensions, and never 'neutralize' them

- sometimes the realm of dimensions is not reduced (Talmy, Vandeloise); but this realm is considered primarily as part of our experience of the external physical world; spatial uses are more than typical, they are the primary ones; and all other uses are considered to be derived by a kind of metaphorical process ${ }^{3}$.

With the semantics of prepositions, we find in a particularly striking form the problem of the relation to space and to the physical world. We shall take this example as a fundamental illustration of the ideas we intend to put forth in this paper. Indeed, the approach we advocate is deeply different from those we have just evoked. ${ }^{4}$ It aims at going beyond these kinds of schematism, while keeping some of their 'good' properties. The exact abstraction level as well as the interior diversity of each scheme are a first key matter. On the one hand, abstract topological and/or cinematic characterizations (call them 'configurational') are too poor. On the other hand, schemes weighted from the beginning by spatial or physical values are too specific, and furthermore rely on a very peculiar conception of spatial and physical experience. Actually, more 'intentional' or 'praxeologic' dimensions, intuitively related to 'interiority', 'animacy', 'expressiveness', 'appropriation', 'control', 'dependence', 'anticipation' etc. are needed. By entering in the process of discourse, all these dimensions configurational or not - can be neatly put forward by speech, or alternately kept inside the dynamics of the construction of meaning as a more or less virtual aspect of what is thematized. In particular, configurational or morphological values are not a systematic basis: they may be pushed in the background, or even disappear, superseded by others, which are quite equally fundamental and grammatical.

More generally, these motifs, as we shall call them as from now, to distinguish them definitely from the problematics we criticize, appear deformed, reshaped, in various profiles, abstract as well as concrete. A motif is a unifying principle for this diversity of uses, which can only be understood if one takes into account from the very beginning dimensions of meaning which cannot be integrated into the narrow frame of a schematism - at least if by a 'schematism' we mean something (still predominant in cognitive linguistics) which can be traced to kantian philosophy (Kant [1781-1787]; for a discussion on this point, cf. Salanskis, 1994). Of course we have to consider all these fundamental dimensions at a very generic level, so as to assume that they are systematically put into play, and worked out by each use. But generic as they may be, our thesis is that these dimensions can be traced back to the immediate experience of perception, action and expression, if they are conveniently

\footnotetext{
${ }^{3}$ As a matter of fact, this second trend is now developing towards a better acknowledgement of the role of action and its anticipations (cf. Vandeloise 2001, and other papers in the same Workshop). In Cognitive Linguistics, until recently, this kind of analysis remained limited to the theory of grammatical constructions and to the semantics of verbs (Fillmore's Case Grammar, Construction Grammar, cf. Goldberg 1995). At the present time, it has evolved to encompass other categories of words, like prepositions, by resorting to so-called 'functional' features.

${ }^{4}$ It draws on several recent works on prepositions (Cadiot 1991, 1997, 1999b).
} 
described in their social and cultural setting. This is why we decided to drop the designation of scheme, and to adopt the word motif to express the kind of 'germ of meaning' we wish to attribute to many linguistic units. Indeed, the word 'scheme' evokes a certain immanentism or inneism, a restricted repertoire of categories not constituted by culture and social practices, and a priviledge granted to a certain biased representation of the physical world. It is therefore a term not suitable for indicating an historical, cultural, 'transactional' unifying linguistic principle, whose function is to motivate the variety of uses of a grammatical or a lexical unit.

\section{Some sketchy considerations on French Prepositions ${ }^{5}$}

There are great differences in the systems of prepositions in French and English, especially concerning so-called 'colourless' or only weakly depictable 'space prepositions' like EN or PAR. We will here present only short considerations about SUR, SOUS, CONTRE, EN, PAR, which evidently call for considerable developments, and should be in a systematic mood confronted to other languages. We hope at least that this will be understood as a way of challenging the routine frozen expression : "spatial preposition".

The case of SUR

A very sketchy analysis allows us to distinguish the following configurations.

A 'region SUR' constructed at the level of predication ETRE SUR ('to be on'), i.e. a construction of a site based on the connection [Preposition + Nominal], localization of the noun subject, and the contact enabled by the predicat :

(1) Le livre est sur la table ('The book is on the table' )

In other cases, the 'region $\mathrm{ON}^{\prime}$ ' is established by the context of the sentence, which allows for an adjustement or requalification of lexical and syntactic expectations.

(2) Max s'est effondré dans le fauteuil ('Max collapsed in the (arm) chair').

(3) Max a posé timidement une fesse sur le fauteuil ('Max timidly sat on the (arm) chair' ).

The motif 'contact' is permitted and enabled by the predicate. As opposed to a table or a sidewalk, an armchair is not a priori an acceptable object for the predicate ETRE SUR ('to be on'). The requalification is facilitated by the specific reference.

A zone established as a frame for what happens in the 'region SUR'. Compared with the previous examples, the possible fluctuations between contact and localization increase.

(4) Les enfants jouent sur le trottoir ('The children are playing on the sidewalk')

\footnotetext{
${ }^{5}$ This section is taken from Cadiot 2002.
} 
Still, there is a simple correlation between a topological notion and a uniquevocal localization in the thematic space.

However, this correlation is nullified, or made more complex, by many other uses with spatial implications. It may happen that the prepositional phrase does not localize the subject of the sentence.

(5) Pierre joue avec sa poupée sur la table ('Pierre plays with his doll on the table').

(6) Pierre a vu un chat sur le balcon ('Pierre saw a cat on the balcony').

Nothing indicates that the referent of 'Pierre' is localized by the 'region ON' (on the table, on the balcony). In fact, the contrary is noticably more likely.

The 'region ON' no longer has determined spatial limits at the thematic level. Following examples are quite particular to French, in which we can hypothesize that the motif is further developed.

(7) Pierre travaille sur Paris ('Pierre works *on/in Paris').

(8) Pierre est représentant sur la région Nord ('Pierre is a representative *on/for/in the north').

Here, the preposition SUR is used in the construction of "functional spaces" (zones specified only in the domain of the predication) and not of physical spaces, but the topological instruction of contact is preserved .

The motif of 'contact', which, based on the preceding examples, we might believe to be simply topological, can actually be easily requalified with new interpretative effects for which the spatial inferences are decreasingly concrete, proving itself to be inseparable from temporal and qualitative modulations (Dendale \& De Mulder, 1997, whence the following examples) :

- support (weight or imminence).

(9) Une menace planait sur la ville ('A threat hovered on?/over the town').

- foundation (assessment).

(10) Juger les gens sur l'apparence ('To judge people on?/by their appearance').

(11) Il fut condamné sur de faux témoignages ('He was convicted on false testimony').

- covering.

(12) La couverture est sur la table ('The tablecloth is on the table')

- objective (goal)

(13) Marche sur Rome ('March on Rome')

(14) Fixer un oeil sur quelquechose ('*pose/ *fix / *leave/feast one's eyes on something'. 
-visibility, immediate access ( as opposed to inclusion which would signify dependance, interposition of a border or a screen).

(15) Il y a un trou sur ta manche ('There is a hole *on/in your sleeve')

Semantic cues 'support' and/or 'foundation' can be extended easily to uses that are definitively 'non spatial' as in:

(16) Impôt sur le revenu ('tax on income')

(17) agir sur ordre ( 'act on orders' )

(18) Pierre a travaillé sur cette question depuis longtemps ('Pierre has been working on this question for a long time').

Or even:

(19) Sur cette question, Pierre n'a rien à dire ('On this issue, Pierre has nothing to say').

Here the motif of contact is invested in a thematic zoning, which can be specified only in the domain opened by the predication or the introductor nominal argument.

Let us also remember the temporal uses differentially specifiable, which emerge from the motif of contact.

(20) Sur ce, il disparut à jamais ('*On/after this he disappeared for ever')

(21) Pierre est sur le départ ('Pierre is about to leave')

(22) Il y a eu des gelées sur le matin ('There was a frost this morning/on the morn' (archaic))

(23) Il faut agir sur le champ ('One must act at once').

In compter sur ses amis ('to count on ones friends'), miser sur le bon cheval ('bet on the right horse'), without entirely abandonning a certain value of 'to lean on', a modulation of the original motif, the preposition is requalified as a rectional marker.

These examples not only invalidate purely spatial and physical explanations of SUR. They also weaken explanations based on abstract topological schemas, which often seem artificial and demand further qualifications which call into doubt their validity. Above all, this type of schematics does not provide operable explanations, and as a result doesn't explain why only certain values and not others are called upon (by interaction with the surrounding lexical material, as we say). What's missing here is the possibility of recognizing the affinity and interrelation of these different values, which we would like to stabilize by way of lexicogrammatical motifs.

In this way, the topological instruction, even when purely configurational and despatialized (i.e. conceived independantly of the perceived space) seems to flag behind a richer, more open definition-delimitation of two 'segments' or 'phases' as they are construed during any type of contact. Compared to the image of 'surface' often invoked (geometrical notion), or to that of 'height' (Weinrich 1989), this motif of 'contact' would have the same statue as that of 'coalescence' for EN, or of 'means' in the case for PAR. Beyond its dynamic value it also offers a static characteristic which provides a border or a stabilized variation (localization, support) but it is fundamentally an aspectual motif, intentional in aim and in practice. At once a motif of exploitation and of valorisation of this contact by a type of immediate interaction (leaning, rebounding, perlaboration), giving the values of objective, 
imminence, achievement, effect, transition, cause and effect. Its configurational expression, once fully deployed, includes an axial orientation of momentum, another transversal orientation for the contact zone and the exteriority maintained between the two phases thus delimited. (if the contact zone is in fact the topological frontier of the access zone, it is still not appropriated as its border, but remains 'exterior' ).

Localization can certainly be explained in euclidean terms : surface, height, width, etc. But the diversity of possible instances of localization (the rich variety of contributing elements) calls for dimensions which are more dynamic (force, figure/background) compared to the more configurational ones. In the phrase cup on the table, we might emphasize the importance of [bearing-weight]. In bandage on the arm, drawing on the wall handle on the door, apple on the branch, ON constitutes the sight as a [background], which guarantees a [detachability] for the figure, regardless of any more objective relations with the object/surface.

\section{The case of SOUS}

One can uncover five 'experiental types' (evidently a nice example of a family resemblance in the wittgensteinian sense):

- low position : sous la table ('under the table'); sous les nuages ('under the clouds');

- covering/protection : sous la couette ('under the covers'); (objet enfoui) sous la neige ('under the snow'); sous une même rubrique ('under/in the same rubric');

- exposition : sous la pluie (under*/in the rain); (marcher) sous la neige ((walk) 'in the snow') ; sous les regards ('under the eyes of x') ; sous les bombes ('under fire') ; sous la menace ('under the gun');

- inaccessibility : sous terre ('underground'); sous le sceau du secret ('under heavy guard');

- depending from the external: sous surveillance ('under surveillance'); sous influence ('under the influence') ; sous la contrainte ('under pressure'); sous garantie ('under warranty') ; sous arrestation ('under arrest').

These uses involve a co-adjustement of the values selected from the NPs assigned by the preposition, and in some cases by the introductory element (see the example of snow). Together they evoke family resemblances of covering, protection, inaccessability, exposure to, and dependence upon, in varying degrees of explicitness ?

Among the notions evoked above, certain seem more oriented to a topological schematic pole (surface constructed by the PP which establishes an interior space based on that boundary. The others closer to a more « instructional » pole (Cadiot 1999) which consists of the more dynamic values, aspectualised by a quasi praxeological perspective (no exit dynamic, opening blocked) indexed on the ambivalence of the situation (covering vs. exposed). Articulating these two poles of the boundary, which remains separate from the interior space, is just the configurational expression of this blocking and ambivalent. As in the case of SUR, this complex motif is diversely profiled and stabilized : by valorization, specification, or on the contrary inhibition, retreat, aspectualization of the different values it unifies.

The case of CONTRE 
Let's note the following four 'experiential types' :

- Proximity with contact : s'appuyer contre le mur ('leaning against a wall' ).

- Opposition (conflict) : être contre le mur de Berlin ('be against the Berlin wall') ; contre toute attente ('against all expectations').

- Exchange : échanger sa vieille voiture contre un scooter ('trade one's old car for.a scooter').

- Proportion / comparison : vingt mauvais films contre un bon ('20 bad films *against/ for one good one').

For CONTRE we propose a motif instituting the affinity of opposition and reconciliation (force/counter-force, posing/opposing). This motif is sustainable, up to a certain point, in a schematic framework, which could be capable of reflecting relational categories like [force] in a plurality of spaces (not necessarily physical). But we insist again that this motif-schema must be modulated and specified in accordance with plausible profiles. As a result values such as 'counter-force' or 'dynamic coming together' can disappear almost completely from the profile. Even when so "virtualized " as in Sofa against the wall they remain as a motivation for the internal perspective or 'aspect' of the dynamic.

\section{The case of EN}

We will show two points:

- there is no clear-cut distinction between spatial and non-spatial uses or senses;

- the specifically linguistic meaning of it should be accessed in an immediate combination of schematic and intentional dimensions:

Let's have a look at folllowing phrases :

(1) pommier en fleurs

(2) chien en chaleur

(3) femme en cheveux

(4) propos en l'air 'apple tree in bloom'

'dog in heat'

'hair-dressed woman'

'words up in the air'

The sense of these phrases can be paraphrazed by following intuitive formulations or characterizations : 'globally saturated physical image' (1), 'invasion' (2), 'emblematic access' (3), 'taken over from the inside/outside' (4).

They tend to show that space is only involved at a thematic level, and in some sort of continuous variation. The characterisations can be resumed in an unique notion, or motif, of coalescence, with no linguistically prescribed limits or 'bornage' (bordering), and assymetricaly oriented toward the referent of the second NP. The image of the first NP is, so to say, absorbed in the image of the second (fleurs, chaleur, cheveux, air).

But this motif is not only schematic or perceptual. It coalesces with a more instructional dimension: one has to associate the resulting image with its perspective, and with the intention through which or by which it was brought about. The scene is necessarily animated by the process which generated it. Otherwise other prepositions like DANS (with its bornage instruction) or even AVEC would be more appropriate.

A more direct evidence for this rather intuitive interpretation can be drawn from other data where space is not involved: 
(5) Max est en faute ('Max is mistaken') / *Max est en erreur

(6) Max est en tort ('Max is wrong') / *Max est en raison

(7) Max est en beauté ('Max is handsome') / *Max est en laideur

(8) Max est en vie ('Max is alive') / *Max est en mort

(9) Max est en difficulté ('Max is in difficulties') / *Max est en facilité.

There seems to be a rather regular paradigm of such cases, where only the 'resulting states' which can be associated with the intentional, subjective object-oriented path, or purpose that brought them about can be correctly introduced by EN. For example Max est en vie is pragmatically possible only in as much as one has reasons to believe that he could be dead (after some accident, presumably); Max est en faute, because he has done or said something which happened to be wrong or inappropriate; Max est en beauté means more than Max est beau : that he tried or at least, wished to be handsome ...

The case of PAR

Even more evidently, it is impossible to differentiate spatial and not spatial uses in the case of PAR.

être emporté par le courant

passer par le jardin

prendre par la gauche

regarder par le trou de la serrure

attraper par la cravate

tuer par balle

convaincre par son comportement

impressionner par son intelligence

passer par des moments difficiles

renoncer par lassitude 'to get carried away by the current'

'to go through the garden'

'to take a lefthand turn'

'to look through the key-hole'

'to grab by the tie'

'to kill by bullets'

'to convince by one's behaviour'

'to impress by/with one's intelligence'

'to come through hard times'

'to give up from/because of lassitude'.

In English, BY works better with active referents and tends to internalize them in the scope of the schema, while with more external complements, THROUGH or even BECAUSE OF are better, and WITH seems at least to initiate a motion of externalization, or 'parallelization'. As is well known, PAR is typically used to express agentivity in passive constructions or in any type of constructions where a process is described from the point of view of its activation. So it expresses an inner activation principle. Being 'inner' corresponds to the schematic dimension, being 'agentive' to the intentional one. But both are intimately correlated and coactive in every instance, even when it corresponds to no specific local thematic or referential intuition.

We stop here this series of examples, and try now to draw some general conclusions. What is actually our own perspective? In summary, we advocate:

- No privilege for spatial or physical usage of words (as conceived by current trends in Cognitive Linguistics), and consequently no doctrine of metaphorical transfer of meaning, 
going from the spatial and/or physical uses towards more 'abstract' ones (as currently conceived by the same linguistics)

- Search for grammatical motifs, which are ways of giving/apprehending/displaying, immediately available in all semantic domains, without any analogical or metaphorical transfer stemming from more specific values, allegedly conceived as the primitive ones

- Rejection (most of the time) of purely configurational versions of those motifs: on the contrary, a motif, especially a grammatical one, is an unstable, and at the same time a strongly unitized, mean of building and accessing 'semantic forms' ; it ties together, and defines a kind of transaction between many dimensions which cannot be dissociated at its level, but at the level of profiling inside specific semantic domains

- Rejection of an 'immanentist' explanation of the variety of uses, based upon an identification of the motif with some kind of 'autonomous' potential; indeed, depending on the specific use, some dimensions of the motif can be further specified, enriched with other dimensions, or on the contrary virtualized, even completey neutralized. The parameters controlling the profiling dynamics are not an internal property of the motif: the relation between the motif and a particular profile has to be considered as a linguistic motivation, because profiling a motif consists of recovering it within other dynamics, brought about by the co-text and the context, i.e. by an ongoing hermeneutic perspective

- A conception of the grammatical motifs (e.g. a motif of a preposition) as highly unstable 'forms' (or germs of forms) which can be stabilized only by interaction with the others constituents of surrounding syntagms, or even by more distant elements of the co-text: as we have said, this stabilization is not a 'simple' instantiation of the motif, but a recapture by other non immanent dynamics giving rise to the variety of its profiles.

Actually, this approach is very general, and applies both to grammar and to lexicon. It is strongly different from other approaches currently worked out by cognitive linguistics. We have already underlined some differences in the analysis of the grammatical expression of space, and in the assessment of its status relatively to the global functioning of the concerned units. But the situation is the same for grammar as a whole, and in particular regarding its difference with the lexical aspects of meaning. In short, we could say that cognitive linguistics tend to limit semantics to grammar, and grammar to a certain kind of 'schemes'. We have just criticized their schematism, as well as the conception of perception to which it is correlated. Indeed, concerning the type of the grammatical schemes, and their relation to our external, everyday perception, we have seen that two main attitudes can be distinguished:

- sometimes, the schemes are from the very beginning merged with a very peculiar conception of the physical world, in which the fundamental role of action, and of other kinds of anticipations, is underestimated (cf. Talmy, or Vandeloise 1991);

- sometimes they are abstract, and purely topological/configurational (Langacker).

The reason for this false alternative is simple: there is no generic diagrammatic representation of action, animacy, interiority, expressivity, intentionality and anticipation, as they are constituted by their cognitive, social, cultural and... linguistic modalities. So that whenever one tries to take some of these dimensions into account, the only way to recover some expressions of them is to resort to the physical experience - which is at the same time wrongly apprehended. Once again, such a conception of our 'immediate experience' not only provokes an impoverishment of the theory of grammar, it also introduces a gap between grammar and lexicon, as well as between the so-called litteral meaning and the figurative ones. Finally, so to speak, the only relation between grammar and lexicon, is... schematism ! And the only relation between the registered basic lexicon and the variety of uses is... a 
metaphoric relation to space! In short, we think that cognitive linguistics have up to now too strongly dissociated 'structure' (identified to the schematical dimensions of meaning) from 'content'. Therefore the very foundation of semantics is still grammar, understood as a fairly autonomous device, in spite of whatever these authors may say about the continuity between grammar and lexicon. In the same way, there is a tendency to see grammaticalization as a pure bleaching process, which only retains values pertaining to a universal repertoire set once and for all.

We think, and actually numerous linguistic analyses show, that we need a richer theoretical apparatus, inspired by an integrated theory of perception, action and expression, really susceptible to be transposed into grammatical and lexical studies, which would then become more tightly unified if we view them in this perspective. We look therefore towards a fully intentional theory of perception, a semiotic and 'transactional' theory of immediate experience, constituted by the simultaneous grasp of practical (praxis), axiological (ethics and esthetics), and subjective values. In order to recover such a theory, we would have to read carefully the gestaltist writings, notably those of the Berlin School (Wertheimer, Koffka, Köhler), the message of which has been weakened by cognitive linguistics. Beyond that, we would have to come back to the phenomenological tradition (Husserl, Gurwitsch, MerleauPonty), to Cassirer's philosophy of symbolic forms, and also for example to Vygotsky's developmental psychology, which gives to social practices a constitutive role. ${ }^{6}$

Once recovered in this way a much more relevant model of perception-and-action, we shall be in a position to transpose it into semantics, in order to provide for a more complex interplay between the dynamics of constitution and the constituted meanings, than anticipated by current schematisms. Language activity will be described as a process analogous to what is called a complex system in other disciplinary areas. Notably, the construction of 'semantic forms' will appear as a kind of microgenetic developmental process, with concurrent unstable and stabilization 'phases'. The description of the linguistic motifs as unstable germs of forms (in a gestalt sense of the word 'form', transposed to semantics) is thus fundamental in our perspective. This will result in three semantics 'modes' or 'phases' in the dynamics of the construction of meaning, which we shall call motifs, profiles, and themes.

\section{Towards a phenomenological and Gestalt theory of Semantic Forms}

\subsection{Gestalt, Phenomenology, and Language Activity}

\footnotetext{
${ }^{6}$ Some among the most important references to the authors quoted in this paragraph are given in the References section. An excellent introduction to Husserl's phenomenology can be found in Salanskis (1998). For an introduction of some of Vygotsky's ideas in cognitive linguistics, cf. Sinha and Jensen de Lopez (2000).
} 
Among the several fundamental references quoted at the end of the preceding section, we shall limit ourselves, and even then in a sketchy manner, to the gestaltist ones. ${ }^{7}$ Gestalt psychology has often been reduced to its morphological and morphodynamical aspects (especially with the famous slogan 'the whole is more than the sum of its parts'). Actually, it describes a much richer and deeper unity between perception, action and expression. It is precisely this kind of unity that we want to put at the core of the construction of meaning, seen as a construction of 'semantic forms'. Under the expression 'semantic forms', we do not refer to a sensation conceived in isolation (even if the theme of the discourse resorts to our concrete, practical world), but to semiotic and multimodal 'forms' unfolding through language activity as units in all domains of thought and experience. We do not either take ordinary perception as a foundation for linguistics, but rather take it, when described according to the phenomenological style, as an essential correlate, and a particular illustration of the construction of meaning. Once again, the choice of a theoretical perspective on the perceptual experience is decisive for any linguistics which pretends to find here a model, and perhaps an origin.

For example, turning back to of our fundamental relationship with space, we find currently in linguistics three main conceptions of this reference space:

- physical, objective space, with a universal geometry, and objective, universal categories of 'objects'

- perceived, psychological space (still independent of culture and language diversity as a general framework - even if it is differently worked out by cultures and subjects)

- semiotic space, whose overall perception bears immediately upon social practices and cultural knowledge

Cognitive linguistics favor conception (b), with a very little touch of (c). We think more radically that:

- this approach of perception should be extended to include a broader repertoire of dimensions, which are unavoidably shaped by the social and cultural context. This repertoire cannot be defined on the basis of a purely pre-linguistic or extra-linguistic perspective. Each particular language defines its own realm of dimensions, including those that are closer to the sensible ones.

- perception, for what concerns its 'continuity' with semantics, is less a matter of encountering concrete, external things or places, than a matter of establishing qualified relations with things, space, and other perceiving agents; therefore another conception of subjective experience, as well as a more intersubjective perspective, are here fundamental; they put forth immediately intertwined attentional, modal, behavioral, axiological values, which cognitive linguistics treat only as secondary or derived, and at best in a very parsimonious way.

What seems to be related to language at its most profound level, in an intimate and reciprocal connection, is the social and cultural Lebenswelt, which includes centrally the socially and culturally constituted experience of the body, in its relationship to its practical environment and to others subjects. Spatialist and/or purely topologist approaches apprehend only certain wrongly isolated effects of this intimate connection. Furthermore, they tend to consider space as already constituted, and do not grasp it at the level where it is

\footnotetext{
${ }^{7}$ Readers interested in having more details on phenomenology and perception, in the perspective of a transposition in the field of semantics, may refer to our book (2001: particularly chap. 2).
} 
permanently reconstructed by our movements, and reshaped by our expectations. Quite differently, we want to insist on the self centered bodily experience, which is exemplified by qualitative terms, like : resistance/yielding, holding tight, rupture, softness, roughness, bury, block, insert, get rid of, drown, touch, etc. Consider also the 'motif' of containment, which is much richer than the relationship between the container and the contained. Think of the motif of control, which intertwines attentional, temporal, kinesthetic, modal, and even intersubjective aspects. Think equally of the English particle up, which is conceptually an aspectual marker for completion, and not essentially an indication of verticality, etc. Meaning is thus firstly anchored in anticipation, qualitative, often synesthesic feelings, and not in a directional grasping of « objects ». But we insist (contra Lakoff) that this partial embodiment of semantics is only possible if the body in question is not considered as a pre-linguistic basis, but as a cultural construction, a truly 'fictive' body, constituted by social practices and among them by language activity.

Precisely, the Gestalt and phenomenological tradition doesn't dissociate the grasping of forms and values; as we said, perception, action, and expression are here more tightly intertwined than in any other approach. 'Forms' in this sense:

- are to be simultaneously defined in all modalities (visual, auditive, tactile, motor and kinesthetic...), cf. the very important concept of synesthesy (objects, moves, changes that appear explicitly in one sensorial modality, are 'felt' in other sensorial and kinesthetic modalities as well)

- have immediate functional and agentive values (degree of spontaneity, distinction active/passive, differentiation of roles). Cf. Gibson's affordances (1979), which have been directly inspired by Lewin's Aufforderungscharakter and Kohler's requiredness (1938): e.g. artifacts like a hammer, a chair, are perceived immediately with their gestual, postural, functional values; seeing a mailbox immediately sketches, depending upon our attitude, parts of an integrated social scenario

- have also immediate esthetic and 'behavioral' values, with emotional resonance. Recall the examples of Köhler $(1929,1938)$ : a wave, a musical crescendo. Cf. also Michotte's work (1946) on the perception of movements as behavioral styles (walking, running [away, after], swimming, flying...)

- include an immediate perception of forces or causes, of intentional moves (intersubjectivity, animacy, agency), and of expressive values (joy, fear, demand...).

Perception in this sense has to be considered as instantiating a general structure of cognition, and not only as resorting to a purely sensorial and peripheral organization. As a slogan, we could say that 'to perceive is from a single move to act and to express'. Perception already gives access to, and sketches, a meaning. It implies not only the presence of things, but a perspective of the subject, and a suggestion of acting. Perception in space is not grasping pure configurations or shapes, nor only a basis for other, subsequent 'associative' or 'metaphorical' interpretations: it is from the outset a dynamic encounter of 'figures' with no necessary dissociation between forms and values, apprehended in the course of actions, and deeply qualified by a specific mode of access or attitude. It is this notion of a qualified relation (which is a way of 'accessing', of 'giving', of 'apprehending'...) that we want to transpose into semantics, in order to view it as a kind of perception and/or construction of forms. At this level, any distinction between abstract or concrete, or between interior or exterior perception, is irrelevant. 
In the same way as there is more than topology or geometry in our multiple relations to ambiant space, we can say that 'figures' are objective counterparts, phenomenological manifestations of the relations we have with them. Needless to say, the perceived relations are not prescribed by some kind of pre-existent exterior world: they are conditioned by a global perspective or purpose, which constitutes subjects and objects simultaneously. Any perceptive relation can thus be modulated towards its subjective side, or towards its objective one, in a way which is constitutive of the act of perceiving. As a relation, it can be transposed to multiple situations or referents. Language only radicalizes this: at its deepest level, it defines, differentiates, and records primarily relations - not the referents, which depend upon another, more thematic, linguistic and cognitive level (e.g. think to a contrast like house/home: possibly the same referent, but not the same relation to it). And as soon as language comes into play, relations are definitely socially constructed, as historically accumulated sediments. On the whole - and this is called polysemy - they are intrinsically transposable to a diversity of 'themes', in a variety of semantic domains correlated to a variety of social and cultural practices. Language activity appears, up to a certain degree, as a 'new' layer of social perception, made of intrinsically transposable, highly unstable germs of 'forms' (forms of relations), to be stabilized in a variety of domains: experiential (qualia and their evaluations), practical (actions and their domains), theoretical, mythical, etc...

Therefore, if the concept of Gestalt seems to be perfectly transposable to semantics, it is on condition that it be rethought so as to integrate the socially constituted nature of Semantic Forms, which are of a linguistic and semiotic nature, different from the more universal level of experience which has been studied in the visual modality ${ }^{8}$.

\subsection{An insight into the semantics of Nouns}

In several recent works, we have applied to a set of strongly polysemic nouns of 'Basic French' a description principle, which takes into account on an equal footing all their uses. ${ }^{9}$ We were thus moving away from the dominant lexicologic approach, which promotes a certain notion of 'litteral' meaning, supposedly combining tangible, concrete, reference and denominative function in a first primary layer. As for us, on the contrary, the meaning of the most frequent nouns can and must be devised long 'before' any logic of classification or of categorization of referents. As a matter of fact, nouns - at least the most frequent ones - are 'ways of access', or 'ways of establishing relationships', prior to being labels in a game of entities categorization and denomination. Their prior function is to be interpreted in terms of analogical generative potentials (or germ of forms), which we called motifs. These motifs may be intuitively presented as generic 'experiential bundles', and described, in the phenomenological and Gestalt style, according to different intertwined modalities: perception, action, qualia and evaluation. Of course, we do not intend to give full descriptions of them: such an enterprise would be endless. The only thing to do is simply to put forward some of their principal dimensions, which are already very enlightening for the

\footnotetext{
${ }^{8}$ But even in dealing with vision, we should not forget that there is the 'seeing as' phenomenon : the way in which we see things depends on the way we name them. Cf. for instance several papers in The $2^{\text {nd }}$ Annual Language and Space Workshop, University of Notre Dame, June 23-24 (L. Carlson, E. van der Zee, ed.): Smith ; Richards \& Coventry ; Tversky \& coll.

${ }^{9}$ Cf. Cadiot 1999a; Cadiot and Nemo 1997a,b ,c; Nemo and Cadiot 1997; Cadiot and Tracy 1997; Visetti and Cadiot 2000; Cadiot and Visetti 2001b, 2001: ch. 3, section 3.1; see also Tracy 1997; Lebas 1999.
} 
question of polysemy and of the so called 'figurative meanings'. We shall give here very few examples, trying to choose them in such a way that their polysemic distribution in French be similar to the one of their usual translation into English. Other examples can be found in Cadiot and Visetti 2001, chap. 3; Visetti and Cadiot 2002, section 3.

Let us start with some motifs which seem to provoke a perception and/or a construction of forms of visual type. The words which correspond to them seem indeed to have as a basic signification a 'schematic' form, which is easily, almost mechanically, transposable from one domain to another.

- ARBRE ('tree'): arbre fruitier ('fruit tree'), arbre généalogique ('family tree'), arbre syntaxique ('syntactical tree'); also some uses considered as more figurative: arbre de la Vie ('Tree of Life'), arbre de la Connaissance ('Tree of Knowledge')

- VAGUE ('wave'): vague d'enthousiasme ('wave of enthusiasm'), vague de chaleur ('heat wave'), Nouvelle Vague ('New Wave')

These examples already show that motifs are not generally limited to configurational values (like a dynamical shape). Indeed, as in the gestaltist theory of visual perception, motifs unify a bundle of synesthetic values going far beyond purely morphological determinations. For example, the motif of ARBRE unifies a branching process with a specific coherence stemming from the root, and giving rise to a perspective of growth, generativity, support. Depending upon the specific use, some of these dimensions are salient, others are pushed into the background, or even vanish. The important point is that language offers the possibility to grasp simultaneously all these aspects, because they are put into transaction with each other, and blend together, giving rise to a kind of coalescence. At the same time, language offers the possibility of dissociating this same unity (up to a certain point), and of enriching it (if needed), in order to give rise to a variety of profiles.

Beyond the synesthetic values just exemplified, other nouns give direct access in their motif to dynamical-functional and practical (action-oriented) dimensions of meaning. Of course, this immediate relation to praxis makes increasingly more problematic the attribution of an original 'material' meaning ! Thus, for instance:

- BOUCHE ('mouth'): can be used in French as in English for a river ('Mouths of the Gange'), a volcano, etc. French also uses it for the subway's entrance (bouche $d u$ métro). One can see that the motif of BOUCHE includes dynamical-functional aspects, roughly evoking 'entry and exit'

- CLEF ('key'): clef anglaise ('adjustable spanner'), clef de voûte ('keystone'), clef du succès ('key of success'), clef du mystère ('key to the mystery'), point-clef ('keypoint'), mot-clef ('keyword'). One can propose that the motif of CLEF unifies 'exclusive access, (un)locking, and accuracy'. One can also see that the word CLEF can evolve according to a mainly perceptual and functional model (clef anglaise, clef de voute), or according to a more explicitly intentional and practical model (point-clef, mot-clef, clef du mystère)

- MUR ('wall') : mur de briques ('brick wall'), mur de Berlin ('Berlin Wall'), se cogner la tête à un mur ('to hit one's head against a wall'), se heurter à un mur d'incomprehension ('to come up against a wall of incomprehension'). These examples show that MUR integrates in its motif 'to separate, to stand up, to surround, to protect, to hit...'. It is to be stressed that an agonistic dimension is already immediately present in this motif, and not subsequently inferred (but of course it is neutralized in many denominative uses). 
Other words yet give access through their motif to a certain general 'quality of sensation', or to a certain 'norm of evaluation', which can be applied to an open set of entities, situations, states, etc., impossible to be determined a priori. These linguistic qualia have of course very important perceptual and emotional correlates, which are like their emblems; but being linguistic, these qualia are of course something else than these perceptible emblems: they are transposable to many kinds of experiences. Here are some examples, about which we shall not try to explicit any motif (except for the first example). We shall only underline that these conjectural motifs are neither concrete nor abstract, being totally entangled, as generic qualia, between physical, psychological, and axiological aspects:

- NUIT ('night') : the motif here tends to split into two sub-motifs, which nevertheless remain linked ; the first evokes darkness: la nuit tombe ('night is falling'), la nuit de l'ignorance ('darkness of ignorance'), la nuit des temps ('the mists of time') ; the second evokes a period of rest : passer une bonne nuit ('to have a good night')

- BOUE ('mud'): s'enfoncer dans la boue ('to sink in the mud'), traîner quelqu'un dans la boue ('to drag someone's name in the mud')

- FOUILLIS ('mess'): ta chambre/ ton article est un vrai fouillis ('your room/paper is a real mess')

- NUAGE ('cloud'): rather than defining a motif, it is better to delineate it through the specific phraseology of the word (idiomatisms), of which it is a unifying principle. For example: les nuages s'accumulent ('clouds are gathering' : in French, it applies to many kinds of situations where a threat is looming, like in English 'to be under a cloud' ); être dans les nuages ('to be in the clouds'); un nuage de tristesse passa sur son visage ('his face was clouded with sadness') ; and inversely, one can talk of un bonheur sans nuages (a happiness without clouds: 'a perfect bliss').

In this search for the motifs, the lexicalized figurative meanings play a very important role. Indeed, they do not function as heavily analogical mechanisms, but on the basis of an immediate promotion of the corresponding motif, which therefore appears as a general access principle, a qualitative relational index, immediately available in a variety of domains.

All these examples show that the notion of Gestalt can only be recast in semantics if it is taken in its widest diversity. Even less of course than for grammatical units, configurational or morpho-dynamical aspects do not suffice, since the motifs merge many other dimensions. As testified by polysemy, by the (so called) figurative meanings, and by their surrounding phraseology, nouns, at least the most frequent ones, register in their most internal kernel the coalescence of all these dimensions, much more than their dissimilation: this is why it is necessary to introduce motifs as unifying principles for the lexical diversity. On the other hand, this kind of unity does not define an invariant: on the contrary, motifs can be dissociated, and sorted out at the lexical level of profiling. Therefore, profiling do not consist in a 'simple' instantiation, but in a recapture of the motifs through more global dynamics: we contend that this process must be understood as a stabilization process, applied to unstable germs. And this leads us to the global theory sketched in the next and last section. 


\section{The Microgenesis of Semantic Forms: Motifs, Profiles, Themes}

Our global theoretical perspective presents language activity as a construction, and/or a perception of semantic forms. That does not mean that we intend to reduce it to the perception or construction of simple 'external' entities. On the contrary, it means that we aim at describing the more specifically linguistic-semantic part of a global process giving rise to 'thematic forms', which are inextricably both linguistic and semiotic. These forms can be sensible, imaginary, or ideal; and their construction depends upon the subject's activity as well as upon the semiotic (social, cultural) ambient medium. This is why we have taken up concepts and principles inherited from the Gestalt and phenomenological traditions: indeed, they put into place, at least at the level of individual subjects, the appropriate setting for this kind of widening of perspective, and at the same time for its focalization on language.

In support of their approach of psychology, the gestaltists from the Berlin School (principally W. Köhler 1920) laid the basis of a general theory of Forms and organizations. Drawing upon their hypothesis of an isomorphism between the structures of the subjective immediate experience, on one side, and the functional dynamical organization of the brain, on the other side, they devised a theory both phenomenological and physical, inspired by field theory, statistical physics, and dynamical systems. But they considered it at that time as a speculative theory, or as a building metaphor, and not as a genuine model for the phenomenological mind and/or for the brain, hoping that future progress in neurosciences, in physics, in mathematics, and in the methodology of phenomenological descriptions, would confirm their insight. Since then, many works in various areas have pursued in the same direction, and actually gone far beyond, towards multiple theories of complex dynamical systems. Although we do not offer here any precise modelization project, we think that calling upon the most general principles of the gestaltist theory of Forms can help to stabilize our own theory, and to prepare its association with the important interdisciplinary field just evoked. As a reminder, here are some of the most fundamental features of this theory: ${ }^{10}$

- Relations between parts and wholes: synthesis by reciprocal determination of all dimensions of the field of forms

- continuous substrates, continuous modulations of forms, and at the same time delineation of forms by means of discontinuities

- figure/ground and trajector/landmark organization

- no form without an 'internal' time of constitution: time of integration and/or differentiation, identification of forms through the dynamical chaining of different profiles

- forms are intrinsically 'transposable' (transposition does not mean a two-step process, going from a field $\mathrm{A}$ to another field $\mathrm{B}$ : it refers to the immediate availability of an organizing 'scheme' in an open variety of domains)

- 'schemes' are not formal types, as in logical approaches, but 'potentials' to be actualized, evolving through practice.

\footnotetext{
${ }^{10}$ For a reconstruction of Gestalt theory, and its assessment in the contemporary field of cognitive sciences, cf. Rosenthal and Visetti, 1999, 2003. For a presentation and illustration of a general dynamical paradigm in cognitive sciences, see Port and Van Gelder (1995), and most of all, J. Petitot's works quoted in the References section. See also Petitot, J., Varela, F., Pachoud, B. and Roy, J.-M. (eds) 1999.
} 
Last, but not least, there appears in gestaltist writings, notably those by the so-called 'microgenetic' schools (Werner 1956; Flavel and Draguns 1957; cf. also Kanizsa 1991: 118; V. Rosenthal, this volume), that forms are to be considered as the result of dynamical stabilization processes, i.e. as units in an ongoing continuous flow, comprising more or less stable 'phases', depending on the moment and on the part of the flow. Of course, for lack of mathematics and physics, it was only possible to develop these concepts of stability/instability as from the 1960's. This more recent aspect of the theory is essential for the theory of semantic forms we want to build. Modern mathematical and physical concepts of instability, and recent advances in the theory of complex systems, allow us, not to modelize for the moment, but at least to conceive and to formulate a unified setting for language activity seen as a construction of forms in a semantic field. ${ }^{11}$ Without taking into account such a notion of instability at the very heart of the linguistic theory, we would be obliged, either to drop the immediate link between language and action-perception (as logical approaches do), or to consider concrete, externally stabilized, referential uses as a first building layer (as cognitive linguistics mostly do). In all cases, this would imply the isolation of literal meanings, and the processing of all other uses by means of metaphor and metonymy (which strangely enough would admit at a later stage transformations such as mixing, deformations, etc. excluded from the first stage).

Let us see now how the dynamical principles we favor are redistributed in our theory.

\subsection{Motifs}

Let us first recall that we view linguistic motifs as unstable germs of semantic forms, which can be stabilized only by, and with: (i) the other constituents of surrounding syntagms, (ii) more distant elements of the co-text, and (iii) an ongoing context-and-topic. This stabilization process is not a 'simple' instantiation, but a recapture of the motifs by non immanent profiling dynamics, partly linked to specific semantic domains, partly constituted by generic grammatical means. All this process gives rise to the variety of lexical profiles (uses) of the words. Each motif blends, intertwines, different dimensions that can be dissociated only later (if ever) in the stabilization process, by inscription into a more specific semantic domain. Therefore a motif does not belong to a specific domain: on the contrary, it encompasses several ones (to the extent that 'semantic domains' can always be sharply distinguished from one another).

${ }^{11}$ Far beyond the remarkable insights of the historical gestaltists, we see now mathematicians, physicists, biologists, computer scientists, modelizers in cognitive, social, ethological and ecological sciences, lay the foundations of a framework crossing their particular domains, and in which questions of stability and instability, invariant and variation, regulation and viability, can be deeply re-thought, and sometimes modelized. The following titles make it somewhat explicit: multiple spatial and temporal scales (at least two, micro- and macro-); importance of the topological, dynamical, and statistical characteristics; reciprocal determinations of local and global aspects; multiple dynamics for the formation of units (births, deaths, coalitions, etc.); co-existence of several dynamical 'phases'; adaptation, and active preservation of the internal and external viability domains; natural drift by coupling with a proper environment; behavioral repertoire organized around unstable dynamical processes, which constitute the system's functional kernel. On the whole, all the system's characteristics are historically determined... Given the great variety of the fields and the models involved, we cannot do better than referring the interested reader to the site of the Santa Fe Institute (www.santafe.edu), and to the entire series of the SFI's Studies in the Sciences of Complexity. See also Weisbuch (1991). For a philosophical analysis of this paradigm shift, cf. Cilliers (1998). 
In a sense, motifs define the functional kernel of many linguistic units, whether monomorphemic or polymorphemic. Most importantly, these unstable 'germs' do not entirely control from the inside their own stabilization parameters, nor are they by themselves generative of the lexical values they motivate. Language activity has a polysystemic, multi-level organization, with strongly interacting and at the same time possibly uncoupled 'levels'. As a physical (thermodynamic) metaphor, this organization is not that of a homogeneous system, made of uniformly individuated and stabilized entities. It is that of a heterogeneous medium, with several coexisting more or less differentiated 'phases', ongoing phase transition, and diffusion/reaction processes.

More precisely, for our dynamical approach of the semantic reconstruction up to the level of text and discourse, we need:

- Coalescence and /or transaction between dimensions of meaning, the dissociation of which could only happen 'downstream' in a stabilization process in the co-text and context: this implies to introduce 'upstream', and constitutionally, a structural instability at the level of motifs (see a little lower in the text);

- Openness and immediate susceptibility of the linguistic motifs within the thematic and situational frame, allowing for a generalized form of indexicality (rooted in the themes of the discourse): because of this plasticity of the motif, and unpredictability of the exact part which is taken up at each occurrence, its internal organization has to be a complex, chaotic one (see lower in the text);

- Permanence of this type of organization through the traditional layers of integration (morphemes, words, phrases, texts).

In order to build such a theoretical linguistic concept, it is quite relevant to draw upon the various mathematical notions of instability. It even appears that we must go further than the Elementary Catastrophe Theory of R. Thom and E.C. Zeeman, from which are inspired the very few existing semantic models. ${ }^{12}$ Pursuing the same lines, we can represent the participation of a given unit in the global construction of meaning (e.g. the contribution of this unit to the construction of an ongoing scene or scenario, or to a network of 'mental spaces') through a dynamical system operating in a certain semantic space, each state of which corresponds to a particular contribution of the unit. This dynamical system is coupled to certain parameters to be found in the co-text and in the context, and it controls in a reciprocal way some (other or the same) parameters in its semantic environment. If the analysis is situated at a microgenetic temporal scale, it is possible to postulate that the essential result of the construction is directed by the 'asymptotic', stabilized states of this dynamical system. In the right cases, the set of all these asymptotic states constitutes an attractor set, i.e. a region of the semantic space (a point, a cycle, or a more complex set, once called a 'strange attractor'), towards which converge all the trajectories, whatever their initial position in a wider region, called a basin of attraction. This attractor set represents a more or less complex state of the unit concerned, which may change according to the contextual parameters influencing the dynamics (and which also reciprocally influences these parameters). Thus, depending upon the contextual variations, a given attractor set can slightly move in the semantic space, without changing qualitatively its internal 'geometry' (structural stability). It can also change qualitatively, or even split up into several other different attractors

\footnotetext{
${ }^{12}$ Examples of semantic models based upon Elementary Catastrophe Theory can be found in Thom (1974) or Zeeman (1977); in Brandt (1986), Petitot (1985, 1992, 1995), or Wildgen (1982); and more recently, with different theoretical orientations, in Piotrowski 1997), or Victorri and Fuchs (1996).
} 
('structural instability', 'bifurcation'). In this way, a linguistic unit appears as a more or less unstable dynamical system, engaged in a reciprocal determination process with a certain part of the context. This 'deformation' process generally results in a more stabilized version of the initial dynamics, which drives the system into a certain attractor set, concentrating, so to speak, the resulting value, or use, of the unit. Hopefully, then, the modelizing process would consist in defining a motif as an unstable dynamical system, and in studying it relatively to a family of possible deformations (i.e. according to the different semantic fields and phrase constructions where the word appears in a corpus), so as to describe exhaustively the different cases of stabilization, as had been once done in other areas by the Elementary Catastrophe Theory.

Structural instability is one of the key concepts of the dynamical system theory. But there is another one, coming from the seminal work of D. Ruelle and F. Takens (1971), and which we have just alluded to (cf . Bergé and al. 1984 ; Dahan-Dolmenico and al. 1992; Ruelle 1993, 1996). Even if the ambient dynamic is stable, its asymptotic states can be very complex, because the corresponding attractor set itself has a very intricate topological structure, constituted by a bundle of dense, entangled trajectories, going through it in an unpredictable way ('strange attractor'). The attractor then represents a chaotic state, i.e. a global envelope of stabilization, which is accurately defined from an ideal geometrical point of view, but the trajectories of which cannot be known in their exact asymptotic evolution (unless the initial conditions are perfectly determined, and the computation 'infinite'). This important property, called 'sensitiveness to the initial conditions', defines a kind of 'stable turbulence', which is of a very high interest for our concept of motif, to the extent that a motif can be promoted as such by certain uses, in particular the 'figurative' or 'metaphoric' ones. In this model, the promotion of a motif corresponds to a chaotically organized state, which results in trajectories inside the semantic space the asymptotic evolution of which remains unpredictable.

We therefore see in which various meanings we need here to take up in semantics the mathematical concepts of instability:

- First within the framework of a stable dynamics, comprising a chaotic attractor set, and consequently a kind of regional instability (allowing the promotion and the contextual elaboration of a motif, with fluctuating trajectories, and unpredictability of what is asymptotically integrated in this kind of use)

- Secondly, in the framework of light global fluctuations of the global dynamical landscape, which do not imply important qualitative transformations (but only amplifications, or a kind of smoothing, inducing more simple or generic variants)

- Thirdly, in the case of genuine structural deformations (structural instability), which modify the topology, and/or the number, of the attractor sets and their basins, and so reveal new principal contrasting dimensions, allowing a whole polysemic diversity of uses.

Let us underline that these phenomena can be simultaneously observed, depending on the dimensions on which the analysis is directed. Moreover, and this is most important, two dynamics can be topologically very similar, and even have exactly the same attractor sets, while strongly differing in their structural instability degree. When this dynamical setting is combined with a 'morphemic' conception of motifs (coalescence, transaction, between dimensions not yet dissociated at this level), several aspects of the construction of meaning, which are ordinarily presented as very distant ones, can be brought together without 
incoherence. Strange as it may appear, 'figurative' meanings appear very akin to the generic 'definitions' devised by lexical studies, and also to the generic 'potentials of meaning' brought out by linguistic theories. As a matter of fact, a generic definition of a motif promotes it through a global description of the topology of its attractor set, which reveals on its ground the intertwining of other linguistic motifs. While a figurative meaning promotes also the motif, not in a synoptic way, but rather by collecting some of its aspects along a largely unpredictable trajectory. ${ }^{13}$ In both cases, the motif, as a dynamical chaotically organized unit, is perceived as such in the discourse - though in a more or less synoptic and global manner. What can be said, then, about the 'meaning potentials', which various linguistic theories postulate in order to introduce some kind of unity and generativity at the heart of a lexical unit ? In a dynamical setting like ours, such a 'meaning potential' is only another structurally unstable form of the motif, topologically very close to its chaotically stable ones (promoted by definition and/or figurative meanings). This structurally unstable form represents in our theory the generative potential of the corresponding linguistic unit, in as far as it is immediately available in an indefinite number of semantic lexical fields, through recapture and re-stabilization within their own dynamical frameworks. Each use then corresponds to a certain stabilization path. In this way, polysemy becomes a central and constitutive phenomenon in language organization and activity.

One sees therefore that it is possible to bring together in a unified setting deeply entrenched aspects of language activity, as well as more innovative ones: the key being to recognize at a theoretical level, and from the very beginning, a certain dynamical state, or semantic 'phase' (let us use here again the thermodynamic metaphor), which potentially combines the different forms of instability we have just mentioned. There remains now to see how this primordial instability is most of the time recaptured, and re-stabilized ('profiled') in order to construct the variety of semantic forms.

\subsection{Profiles}

What do we then call profiles, or profiling $?^{14}$ Roughly speaking, profiling, which is of course context-and-situation dependent, occurs:

- by stabilization in lexical organizations (e.g. domains like music, cooking, sailing, architecture, business, law, mathematics; fields articulating several experiential domains and practices; denominative paradigms...)

- correlatively through grammatical units and constructions

- also through discourse organization (e.g. anaphors, comparisons).

From the point of view of the present theory of semantic forms, profiling implies:

- figure/ground repartition of the lexical content in semantic fields ${ }^{15}$

${ }^{13}$ This being said, the event of a figurative meaning does not only involve the level of motifs ; it also implies processes at the thematic level: e.g. blendings, according to Fauconnier (1997) or Fauconnier and Turner (1999).

${ }^{14}$ We use the same term as Langacker (1987), but in a different theoretical framework. There is no theory of instability in Langacker's cognitive grammar. Furthermore, we have already criticized the strictly 'configurational' schematism he makes use of at the level of grammar. Lastly, we do not have the same conception of the 'thematic' level, nor of the alleged primacy or typicality of physical uses.

${ }^{15}$ The ground of a semantic field corresponds to its most generic features, and also to some more specific, but less relevant or salient ones, when the field is dynamically stabilized by the occurrence of a specific lexical profile (playing here the role of a figure). 
- possible dissociation of the involved motifs, through stabilization in co-text and context

- enrichment by new aspects, or on the contrary impoverishment of the involved motifs.

By this process, words (initially considered with all the 'morphemic openness' of their motif) become lexical units indexed on lexical classes, with more stabilized and individualized meanings. ${ }^{16}$ Plasticity of the motifs through profiling is a key point in our theory. Depending on the reciprocal determination of the co-text and the context, some features can be completely neutralized, or on the contrary made salient. In many cases, some features are so to speak virtualized: they remain as a possible 'aspect' inside the dynamics of construction, without being explicitly integrated in the constructed forms. Nevertheless, they are as it were reserved, and can come back to the foreground if the discourse needs it afterwards. One of the reasons of these virtualization processes is that, by entering in a specific semantic domain to contribute to the formation of a lexical unit, a motif functions as a simple motivation: its proper contribution can be superseded by other afferent features, which are more important in this context. These features are either recorded in the lexicon, as a particular use of the word, or indexically integrated on the spot. But let us underline that even if these modulations of meaning are already registered in the lexicon, it is always the global stabilization dynamics in the current phrase, or in a larger co-text, and the peculiarities of the ongoing topic, which determine what exactly will be taken up from the lexical registration. Let us also underline that profiling is a differential process, which happens through contrasts and coordination between several inter-defining lexical units, which are the results of reciprocal stabilization paths.

At the level of a clause, lexical profiles stabilize through grammatical units and constructions, whose meanings stabilize correlatively at the same time. In this way, each statement appears as a view on the ongoing thematic organization, offering individuation, hierarchical structure, chaining, and grounding in the situation. In particular, a lexical profile can offer a certain view, or aspect, of a thematic unit. But this view is only a characterization of the unit: it cannot by itself decide what constitutes the thematic identity of the unit throughout the discourse. ${ }^{17}$

The determination of a profile is not in the first place a matter of type instantiation, even if pre-recorded types can come into play. Types, in our view, are anticipations which pertain to the thematic level of language organization (like scenarios or 'actors'). The determination of profiles is performed, more fundamentally, by the mobilization of multiple frameworks which open the way to the thematization process Among the most current frameworks are the:

- modulation of specific differences of a lexical unit on the generic ground of a class: a lexical class appears as an area in a semantic space, where features, depending on the considered unit, circulate from the fore to the background (allowing, for example, metonymical shifts: school considered as a building, or as an institution)

\footnotetext{
${ }^{16}$ Not all words, however, possess a specific motif. Numerous technical terms are actually words indexed in a unique specific domain, which furthermore are very rarely used in a figurative meaning (examples chosen at random in a dictionary: galvanoscope, gastritis, gasoline). Of course, speech can always unlock the semantic game, and invent new meanings, which imply the creation of new (most of the time transitory) motifs. As an exercise, try for instance to say to your best friend : You are a real gastritis, or You are my favorite gasoline, and see what happens.

${ }^{17}$ Take for example a cooking recipe : the identity of the chicken (the central actor of the ongoing scenario) remains the same throughout. And nevertheless, its profiles change constantly, from the market up to the plate.
} 
- elaboration of functions and mereology, through lexicalization of parts and functions (a gaming table has legs, but a table of contents has not)

- exploration of the semantic neighborhood (synonyms, antonyms)

- fixation of an hyperonym, i.e. choice of a lexical unit bringing to the foreground some generic features of a given semantic class

- introduction of a scalar structure into a class (e.g. few, many, too many; icy, cold, tepid, warm, hot); more generally, introduction of a global 'geometrical' structure into a class (putting for example a week, generic value at the center, and a dense, emblematic parangon on the periphery ${ }^{18}$ )

- dissociation between processes, and roles or participants

- choice of a part of speech (nouns, verbs...)

- quantification, determination

- aspects, tenses, modalities

- constructions and grammatical functions.

As one can see, the problem of the construction of the lexicon, in its relation to the functional kernel of language (motifs and grammar), pertains indeed to the problematic of complex systems. First, the systemic variation is organized around unstable dynamics (here called motifs), which produce by being stabilized the diversity of profiles, whether new or registered. Secondly, there is a permanent adjustment of the system's categorization networks. The lexicon is not a set of labels, nor a nomenclature of concepts processed as such by the arrows of reference. It is the historical and heterogeneous result of a multitude of accesses to themes; these accesses are never registered alone, but in clusters, and at different depths of unification, stabilization, and exteriorization. The lexicon can only function because it is liable to establish in its own formats, and to register immediately, distinctions up to then original - which implies to weaken or 'virtualize' other already established distinctions, without loosing them. Lastly, the mobilization of motifs and profiles is aimed at the construction of thematic targets, which have their own structure. But language activity is not to be seen as a complete resorption of these semantic phases into a completely stabilized and/or externalized thematic level. It rather rests on the permanent co-existence of these different phases of meaning through the discourse.

\subsection{Themes}

In order to complete the presentation of our theory of semantic forms, we must say at least a few words concerning the level of thematic forms and thematic spaces (recall that we take here 'thematic' in the full, literary sense of the word). At this level, the aggregation of profiles into thematic forms distributed throughout the text or the flow of speech (referring for example to narrative entities like actors, actions, and their transformations) is performed. In the same way as we have recalled in section 3 some principles from the phenomenological and Gestalt theory of perception and action, in order to transpose them into semantics, we should now come back to the phenomenological and semiotic theory of the thematic field (notably in A. Gurwitsch's work), in order to connect our theory of semantic forms, to the contemporary works on discourse, narratives, text semantics, etc. It would allow a criticism

\footnotetext{
${ }^{18}$ A same word can possibly be placed in either position, e.g. the word street which functions according to the case as the generic term of the paradigm of urban ways (avenue, boulevard, lane, etc.), and as a kind of 'parangon' in denser (at the same time metonymical and somewhat figurative) meanings, like to run about the streets, to find oneself out on the street, to come down into the street, man in the street...
} 
of the objectivist approaches, often correlated to referential semantics, and to the primacy of denominative uses. And it would also open the way to describing the new, original, motifs created by the discourse which elaborates, in a more or less innovative way, the pre-given linguistic motifs.

In the framework of the present paper, we shall limit ourselves to the following fundamental points: ${ }^{19}$

- In a situation of spontaneous speech, profiles are not perceived separately from the themes to which they give access, being nothing else than the transitory presentation of these accesses. The profiling dynamics cannot really enter into a stable state without a minimal thematic positioning, including the grasping of an ongoing topic. Profiling therefore depends constitutionally upon the global thematization movement.

- At the thematic level is carried out a global dynamics of construction and access to themes which are set as common objects of interest in the intersubjective field. Themes, in this sense, are partly externalized in our perceptive and practical world, as concrete objects or as effective actions. But this is only a partial aspect of their identity which is made, as already said, of an organized history of profiled accesses (e.g. an history developed in the structure of a scenario). Language opens on an exteriority which can be simultaneously sensible, imaginary, and ideal. We are here in a complete opposition to certain referential semantics, which pretend to favor concrete denominative uses, but actually have a very limited conception of what 'reference' means. To refer to a theme is not only to refer to its concrete facets, nor only to refer to its abstract, ideal, ones. Such conceptions do not allow to understand that language by nature addresses fiction as well as reality. Think for example of a chess game, and its pawns; the theme of the game is a synthesis of many different aspects; and necessary as they may be, pawns are a simple material substrate, invested by this whole thematic organization; or, more precisely, their visible and tangible configuration only defines a crucial perceptive facet of the ongoing theme - i.e. of the game.

- A thematic unit builds up its identity through a synthesis of successive profiles: an actor, for example, is identified by the open set of the participant profiles, which compose it from one clause to another, and define in this way its transformations and interactions with the other actors in an ongoing narrative (once schematized by the scripts and frames of the psychological semantics).

- The thematization activity can and must be understood at the semantic level of its linguistic accesses and effects, and without contradiction, as a global access to other of its textual, pragmatic, imaginary, conceptual, perceptive, and practical layers, which are less directly linguistic, but still semiotic (therefore cognitive and social at the same time).

The concept of motif, as we have seen, has allowed us to describe the functional kernel of language, and its unfolding in a permanently adjustable lexicon. But speech does not only stabilize, it also renews linguistic and lexical instability. Existing motifs are modulated, and new ones are sketched (even deeply elaborated), through discourses some of which are the

\footnotetext{
${ }^{19}$ For more details, see Cadiot and Visetti (2001 : ch. 3, section 3.2.3) ; Visetti and Cadiot (2002, section 4.3).
} 
starting point of an instituted modification, effectively registered in diachrony. It is therefore crucial that the dynamical structure of motifs (which is, so to speak, the most internal 'phase state' of language) allows an immediate interaction with the ongoing thematics. This kind of susceptibility makes it possible to index on an existing lexical unit a renewed motif, which condenses some essential dimensions of a new original theme, after having cut out part of its structure (e.g. its precise event structure). Of a prime importance are here the metaphoric innovations, and in a more commonplace manner, the uses mixing metonymic shifts and figurative operations. ${ }^{20}$

This a complete reversal relatively to other theories, which start from an ontology conceived independently from language, or give primacy to the reference to a concrete, perceptible world, without asking what perception or practice consist of, when they are affected by language. Ontologies are complex thematic constructions, they are a very peculiar result of text, discourse, and other social practices, and not a universal starting point for semantics. Quite differently, we consider as a very important clue for the study of motifs in lexical semantics the figurative meanings, which precisely transgress ontological divisions. As we have said, we postulate that in many cases this kind of use promotes a linguistic motif, i.e. elaborates and puts it forward without absorbing it completely in a conventionalized lexical profile. We gave examples concerning nouns in section 2.

\section{Conclusion: the nature and place of Grammar in a dynamical theory of Semantic Forms}

In this paper, we have systematically analyzed the principles according to which it is possible to build an analogy, and even a continuity, between language and perception. Starting from the case of prepositions, we identified several obstacles, or misleading choices currently made by cognitive linguistics. In particular:

- an erroneous model of perception, strangely disconnected from action, expression, and other essential dimensions of anticipation, leading to an inadequate separation between grammar and lexicon

- the non-taking into account of polysemy as a fundamental property of language

- an inability of the theory to allow the necessary interactions between the thematic developments in discourse, and the presumably most 'interior' level of language (the level of the so-called 'schemes' in cognitive linguistics).

In order to remedy all these deficiencies, we have introduced a more radically dynamical setting, which gives a fundamental role to the mathematical concepts of instability. On this basis, the construction of Semantic Forms can be distributed between three 'phases' named motifs, profiles, and themes. Indeed we claim that a theory of forms, suited to linguistics and susceptible to offer a coherent and global view on language activity, is possible only by introducing a diversity of concurrent semantic 'phase states', in a process made of structurally unstable or chaotic resources, and of partial stabilization dynamics (like in complex systems models).

\footnotetext{
${ }^{20}$ Cf. for example Fauconnier and Turner (1999), Coulson and Fauconnier (1999).
} 
In this way, we rejoin a Humboldtian conception of language, which considers it as an energeia, i.e. not as a finished product, but as a self-organized activity. This implies that we consider languages, not only as means to build (re)presentations, but also as capabilities of being immediately modulated, transformed, by their own activity. In order to better support this conception from a cognitive point of view, it appears necessary to come back to phenomenological and Gestalt theories of perception and action. In this way, the discussion is really opened on what can rightly be taken up again from them for semantics, while not forgetting the historical, social, and 'transactional' nature of what we have called linguistic motifs and lexical profiles.

We can now return to the question of the nature of grammar, and its relation to experience. We will stress the following points:

- Beware of the reduction of grammar to a universally pre-linguistically defined set of features. There should be NO prejudice concerning what the grammar of such or such language is: therefore NO 'a priori' or 'transcendental' approach, despite universal anthropological constraints. Think for example of the so-called 'classifiers' of many languages (Bantu, Amerindian, Australian), whose semantics and constructional properties do not fit well with the categories of the dominant Western-centered tradition. Let us not forget that grammars as well as languages are historical constructions, and that for a given language, grammatical routines are different depending upon types of discourses.

- Beware of the inadequate models of perception and/or schematism, and beware of an excessively focus on the relation to space. What matters first is the global framework of the perceptive and practical experience, apprehended from a point of view which, paradoxically, has to be bodily, subjective, and social. This subjective-and-social experience has also to be apprehended in its microgenetic structure.

- EXPERIENCE does not mean intuition + categories, like in a Kantian approach. It first means perception + action + expression. It is crucially made of anticipations, which are lived as such, and therefore are recursively anticipations of anticipations, etc.

- Grammar, being the set of the most necessary and generic form-creating devices operating in language activity, is:

- not a set of morphological axioms for a purely formal (logical or topological) intuition

- not a set of anticipations of an 'externalized' and 'stabilized' perception, taken in a narrow sense

- Grammar can be more safely compared to the set of the most necessary and generic linguistic anticipations of the subjective-and-social experience of speakers. Grammatical anticipations contribute to the stabilization of both the subjective and the objective sides of the utterance production dynamics, which constitutes at the same time the speaker/hearer and the current theme of interest.

- If experience and language activity are understood as a microgenesis of forms, we have to redistribute these generic anticipations among several concurrent 'phase states' of 
meaning arising in the thematization movement (i.e. in our theory, among motifs, profiles, themes). So the 'genericity' of grammar cannot be assigned to a unique level of stabilization and/or genericity: grammatical anticipations concern different microgenetic phases in the 'thematisation' dynamics.

- As a simplified working definition, grammar should be centered on the most generic 'gestalt-and-synoptic' aspects of the construction of Semantic Forms, i.e. on the generic profile of the Semantic Field (e.g. grammatical constructions). But actually, we have to take also into account the most generic dimensions of motifs, and the most generic thematic devices ('grounding' indexical markers, like deictic, determinant, etc.).

- Beyond the question of knowing what 'generic' and 'necessary' means, the grammatical/lexical distinction amounts to: time)

- the question of the proper appearance time of forms (synoptic vs developed in

- to an impossible clearcut distinction of strongly dissociated units (e.g. constituents) among the variety of semantic forms.

How is then the alleged unity of a word constituted - at least for those languages where the notion of 'word' is relevant ? Our description makes it a compromise between three concurrent dynamic integration formats. At this level of the word (and even beyond in the case of compound lexical units), our theory puts in the center a 'phase state' of meaning, the instability of which (structural instability, instability in the sense of chaotic structures) can be described as morphemic. It makes possible the coalescence of dimensions which can be dissociated only further in a stabilization process, and thus radically differentiates motifs from what other theories call types. Motifs are generic in a specific sense, since they allow homogeneous thematic developments, as well as heterogeneous thematic dissociations or blendings, as in figurative meanings. From this point on, the question of polysemy can be redistributed in a new way among the three postulated meaning 'phases'. It is also possible then (see Cadiot and Visetti, 2001 ch. 4; also 2001b) to take into account the immediate interaction between the ongoing discourse, and the linguistic anticipations registered at these three levels, whether in the time of a conversation, or of a literary work, or also in the general evolution of language in diachrony.

\section{References}

Anscombre, J.C. and Ducrot, O. 1983. L'argumentation dans la langue. Liège/paris: Mardaga.

Benveniste, E. 1966/1974. Problèmes de Linguistique générale. (2 Vol). Paris: Gallimard. Partial Transltion 1973. Problems in General Linguistics (Miami Linguistics, No 8). Miami: Miami University Press.

Bergé, P., Pomeau, Y. and Vidal, C. 1984. Order within Chaos: Toward a Deterministic Approach to Turbulence. NY: Wiley.

Brandt, P.A. 1992 [1986]. La charpente modale du sens: Pour une Sémiolinguistique Morphogénétique et Dynamique. Amsterdam: John Benjamins.

Bühler, K. 1990 [1934]. Theory of Language; The Representational Function of language. Translated by D.F. Goodwin. Amsterdam: John Benjamins.

Cadiot, P. 1991. De la grammaire à la cognition, la préposition POUR. Paris: Editions du CNRS.

Cadiot, P. 1997. Les prépositions abstraites en français. Paris: Armand Colin. 
Cadiot, P. 1999a. "Principe de conformité et génération analogique en sémantique nominale." Verbum 31: 383 407.

Cadiot, P. 1999b. "Espaces et prépositions.” Revue de Sémantique et pragmatique, 6: 43-70.

Cadiot, P. 2002. "Schemas and Motifs in the Semantics of Prepositions." In Prepositions in their syntactic, Semantic and Pragmatic Context, S. Feigenbaum and D. Kurzon (eds): 41-57. Amsterdam, John Benjamins.

Cadiot, P. and Nemo, F. 1997a. "Propriétés extrinsèques en sémantique lexicale." Journal of French Language Studies, 7: 1-19.

Cadiot, P. and Nemo, F. 1997b. "Pour une sémiogenèse du nom." Langue Française, 113: 24-34.

Cadiot, P. and Nemo, F. 1997c. "Analytique des doubles caractérisations.” Sémiotiques, 13: 123-145.

Cadiot, P. and Tracy, L. 1997. "On n'a pas tous les jours sa tête sur les épaules.” Sémiotiques, 13: 105-122.

Cadiot, P. and Visetti, Y.M. 2001a. Pour une théorie des formes sémantiques: motifs, profils, thèmes. Paris: Presses Universitaires de France.

Cadiot, P., Visetti, Y.M. 2001b. "Motifs, profils, Thèmes: une approche globale de la polysémie." in Cahiers de Lexicologie, 79, 2001-2, p. 5-46.

Cadiot, P., Visetti, Y.M. 2002. "Motifs linguistiques et construction des formes sémantiques. Schématicité, généricité, figuralité". Actes du colloque Representations du Sens linguistique, LINCOM Europa, LINCOM Studies in Theoretical Linguistics.

Cassirer, E. 1946 [1924]. Language and Myth. Translated by S. Langer. Reprint by Dower Publications.

Cassirer, E. 1953 [1923]. The Philosophy of Symbolic Forms. Vol 1: Language. Translated by R. Manheim. New Haven: Yale University Press.

Cilliers, P. 1998. Complexity and Postmodernism. Understanding Complex Systems. London: Routledge.

Coulson, S. and Fauconnier, G. 1999. "Fake Guns and Stone Lions: Conceptual blendings and Privative Adjectives." In Cognition and Function in Language, B. A. Fox, D. Jurafsky and L. Michaelis (eds), 143158. Stanford, California: Publications of the CSLI.

Culioli, A. 1990/1999. Pour une linguistique de l'énonciation (3 Vols). Paris: Ophrys.

Dahan-Dolmenico, A., Chabert, J.-L., and Chemla K. (eds) 1992. Chaos et déterminisme. Paris: Seuil.

Ducrot, O. 1984. Le dire et le dit. Paris: Minuit.

Fauconnier, G. 1997. Mappings in Thought and Language. Cambridge, MA: Cambridge University Press.

Fauconnier, G., Turner, M. 1999. "Metonymy and conceptual integration.", in Metonymy in Language and Thought, K.U Panther and G. Radden (eds), 77-90. Amsterdam: John Benjamins.

Flavel, J. and Draguns, J. 1957. "A Microgenetic approaach to perception and thought." Psychological Bulletin, 54, 3: 197-216.

Gibson, J.J. 1979. The Ecological Approach to Visual Perception. Boston: Houghton-Mifflin. Reprint Hillsdale, N.J.: Lawrence Erlbaum Associates, 1986.

Goldberg, A. 1995. Constructions. A Construction Grammar approach to Argument Structure. Chicago: Chicago University Press.

Gurwitsch, A. 1964. The Field of Consciousness. Pittsburgh: Duquesnes University Press.

Gurwitsch, A. 1979. Human Encounters in the Social World. Pittsburgh: Duquesnes University Press.

Husserl, E. 1982 [1913]. Ideas pertaining to a Pure Phenomenology and to a Phenomenological Philosophy. First Book: General Introduction to Pure Phenomenology. Translated by F. Kersten. The Hague: M. Nijhoff.

Husserl, E. 1989 [1912-1928]. Ideas pertaining to a Pure Phenomenology and to a Phenomenological Philosophy. Second Book: Studies in the Phenomenology of Constitution. Translated by R. Rojcewicz and A. Schuwer. Dordrecht: Kluwer Academic Publishers.

Husserl, E. 1973 [1939]. Experience and Judgement. Translated by J.S. Churchill and K. Ameriks. London: Routledge and Kegan Paul.

Kanizsa, G. 1991. Vedere e pensare. Milan: Il Mulino.

Kant, I. 1999 [1781/87]. Critique of Pure Reason. P. Guyer and A.W. Wood (eds). Cambridge: Cambridge University Press.

Köhler, W. 1920. Die physischen Gestalten in Ruhe und im stationären Zustand. Berlin: Braunschweig. Excerpts in A Source Book of Gestalt Psychology 1938. W. D. Ellis, (ed.). London: Kegan Paul.

Koffka, K. 1935. Principles of Gestalt Psychology. New-York: Harcourt Brace.

Köhler, W. 1964 [1929]. Gestalt psychology. New York: Liveright.

Köhler, W. 1938. The Place of Value in a World of Facts. New-York: Liveright Pub.

Köhler, W. 1971. Selected Papers. Ed. by Mary Henle. New-York: Liveright.

Lakoff, G. 1987. Women, Fire and Dangerous Things. Chicago: University of Chicago Press.

Langacker, R. 1987, 1991. Foundations of Cognitive Grammar (2 vols). Stanford: Stanford University Press.

Langacker, R. 1999. Grammar and Conceptualization. Berlin/New-York: Mouton de Gruyter.

Lebas F. 1999. L'indexicalité du sens et l'opposition 'en intension' / 'en extension'. PhD Thesis. Paris: Université Paris 8. 
Merleau-Ponty, M. 1962 [1945]. Phenomenology of Perception. Translated by C. Smith. London: Routledge and Kegan Paul.

Merleau-Ponty, M. 1973 [1969]. Prose of the World. Translated by J. O'Neill. Northwestern University Press.

Michotte, A. (1946). La perception de la causalité. Louvain: Études de Psychologie, Vol. 8.

Nemo, F. and Cadiot, P. 1997. "Un problème insoluble?". Revue de Sémantique et Pragmatique, 2 : 9-40.

Petitot, J. 1985. Morphogenèse du sens. Paris: Presses Universitaires de France. English version to appear 2001. Bern: Peter Lang.

Petitot, J. 1992. Physique du sens. Paris: Editions du CNRS.

Petitot, J. 1995. "Morphodynamics and Attractor Syntax. Dynamical and Morphological Models for Constituency in Visual Perception and Cognitive Grammar." In Mind as Motion: Explorations in the Dynamics of Cognition, R. Port and T. Van Gelder (eds), 227-281. Cambridge: MIT Press.

Petitot, J., Varela, F., Pachoud, B. and Roy, J.-M. (eds) 1999. Naturalizing Phenomenology. Issues in Contemporary Phenomenology and Cognitive Science. Stanford: Stanford University Press.

Piotrowski, D. 1997. Dynamiques et structures en langue. Paris: Editions du CNRS.

Port R. and Van Gelder, T. (eds) 1995. Mind as Motion: Explorations in the Dynamics of Cognition.

Rastier, F. 1987. Sémantique interprétative. Paris: Presses Universitaires de France.

Rastier 1997 [1989]. Meaning and Textuality. Translated by P. Perrone and F. Collins. Toronto: University of Toronto Press.

Rastier, F. 2000. "On Signs and Texts : Cognitive Science and Interpretation.” In Semiotics as a Bridge between the Humanities and the Sciences, P. Perron et al. (eds), 409-450. New-York/Toronto : Legas Press.

Rastier, F. 2001 [1994]. Semantics for Descriptions. To appear. Chicago: University of Chicago Press.

Rosenthal, V. and Visetti, Y.M. 1999. "Sens et temps de la Gestalt." Intellectica, 28: 147-227.

Rosenthal, V. and Visetti, Y.M. 2003. Köhler. Paris: Les Belles Lettres.

Ruelle, D. and Takens, F. 1971. "On the nature of turbulence." Communications in Mathematical Physics 20: 167-192

Ruelle, D. 1993. Chance and Chaos. Princeton: Princeton University Press.

Ruelle, D. 1996. Turbulence, Strange Attractors, and Chaos. World Scientific Series on Nonlinear Science, Series A, Vol. 16. World Scientific Publishing Co.

Salanskis, J.-M. 1994. "Continuity, Cognition, and Linguistics.”, In Continuity in Semantics, C. Fuchs and B. Victorri (eds), 127-153. Amsterdam: John Benjamins.

Salanskis, J.-M. 1998. Husserl. Paris: Les Belles Lettres.

Sinha, C. and Jensen de Lopez, K. 2000. "Language, Culture and the Embodiment of Spatial Cognition." Cognitive Linguistics 11-1/2:17-41.

Talmy, L. 2000. Towards a Cognitive Semantics (2 Vols). Boston: MIT Press.

Thom, R. 1980 [1974]. Modèles mathématiques de la morphogenèse. Paris: Christian Bourgois.

Tracy, L. 1997. "La clé du mystère : mettre le référent à sa place." Langue Française, 113: 66-78.

Vandeloise, C. 1991 [1986]. Spatial prepositions: A Case Study for French. Translated by A. Bosch. Chicago: University of Chicago press.

Vandeloise, C. 2001. "Force and function in the development of the preposition IN.". The $2^{\text {nd }}$ Annual Language and Space Workshop, University of Notre Dame, June 23-24 (L. Carlson, E. van der Zee, ed.)

Victorri, B. and Fuchs, C. 1996. La polysémie - construction dynamique du sens. Paris: Hermès.

Visetti, Y.-M. 1994. "Les modèles connexionnistes entre perception et sémantique." Sémiotiques 6-7: 15-48.

Visetti, Y.-M. 2001. “Constructivismes, émergences : une analyse sémantique et thématique.”. To appear in Des lois de la pensée au constructivisme, M.J. Durand (ed.). Paris: Editions de la Maison des Sciences de l'Homme.

Visetti, Y.-M. and Cadiot, P. 2000. "Instabilité et théorie des formes en sémantique - pour une notion de motif linguistique." TLE (Théorie, Littérature, Enseignement), 18 : 137-169. Vincennes/Paris: Presses Universitaires de Vincennes.

Visetti, Y.-M., Cadiot, P. 2002. "Instability and the Theory of Semantic Forms" In Prepositions in their syntactic, Semantic and Pragmatic Context, S. Feigenbaum and D. Kurzon (eds) : 9-39. Amsterdam, John Benjamins.

Vygotsky, L. 1978 [1930]. Mind in Society: The Development of Higher Psychological Processes. Cambridge, MA: Harvard University Press.

Vygotsky, L. 1986 [1934]. Thought and Language. Cambridge, MA: Harvard University Press.

Weisbuch, G. 1991. Complex Systems Dynamics. Santa Fe Institute Studies on the Sciences of Complexity. Addison Wesley.

Werner, H. (1956). Microgenesis and aphasia. Journal of Abnormal Social Psychology, 52, 236-248.

Wertheimer, M. 1959 [1945]. Productive thinking. New York: Harper.

Wildgen, W. 1982. Catastrophe Theoretic Semantics. An Elaboration and Application of René Thom's Theory. Amsterdam: John Benjamins.

Zeeman, E.C. 1977. Catastrophe Theory: Selected Papers 1972-1977. Mass: Addison-Weslay. 